\title{
Calculation of Gamma and Neutron Parameters for Some Concrete Materials as Radiation Shields for Nuclear Facilities
}

\author{
A. M. Madbouly and Amal A. El- Sawy \\ Radiation Safety Department, Egyptian Nuclear and Radiological Regulatory Authority \\ (ENRRA) \\ Corresponding Author E-mail: amal_sawy@yahoo.com
}

\section{Abstract}

Radiation shielding of nuclear facilities is essential for protection of people and environment during normal operation and accidental conditions. In the present work, the standard concrete is chosen as a primary shield and five materials (Boron carbide $\left(\mathrm{B}_{4} \mathrm{C}\right)$, Ilmenite $(\mathrm{FeTiO})$, Ferroboron $(\mathrm{FeB})$, Galena $(\mathrm{PbS})$ and Barite $\left(\mathrm{BaSO}_{4}\right)$ ) have been chosen to be added separately to it with $20 \%$ in weight. We investigated the shielding parameters viz. mass attenuation coefficients $\square_{\mathrm{m}} \square \square$ for gamma rays which computed by using Win-XCOM program, macroscopic effective removal cross-sections for fast neutrons $\Sigma_{R}$, the absorption macroscopic cross section of neutrons $\Sigma_{\mathrm{a}}$, scattering macroscopic cross section of thermal $\Sigma_{\mathrm{s}}$ thermal and epithermal $\Sigma_{\text {s epithermal }}$ neutrons, relaxation length $\lambda$ and moderate ratio (MR) have been calculated theoretically for these concrete materials. The results have been shown that the concrete containing galena is suitable for gamma-rays and fast neutrons as it has large weight fraction of high- $Z$ as compared with others, while concrete containing barite materials is the best moderator for neutrons. Also, the concrete contains $\mathrm{B}_{4} \mathrm{C}$ is the best for absorption of neutrons, while barite is the best materials for scattering of neutrons. This study is useful for enhancing the shielding design and radiation protection in the nuclear facilities.

Keywords: Concrete, Shielding Materials, Gamma, Neutron, Mass Attenuation Coefficients, Macroscopic Cross Section, Relaxation Length, Moderate Ratio.

\section{1- Introduction}

Protection of biological entities from the harmful effects of radiation exposure is fundamental requirement in the application of nuclear technology. Hence, an adequate protection is needed to ensure people and environment around the nuclear facilities is safe from any harmful effects of ionizing radiation. Radiation exposure can be avoided by methods involving time, distance and shielding. Shielding is the most important method as compared to the others. Typically, concrete is widely used as radiation shielding in many nuclear facilities. Concrete is mainly made up from cement, aggregates and water. The properties of the materials used in the concrete give significant affect to the radiation shielding capability of the concrete [1,2].

Concrete is a cheap, multiuse and widely used construction material. It is related with its efficiency, flexibility, and simple manufacturing process. Among the evident advantages of concrete are: high strength, good insulation properties, durability and the ability to take any shape. Concrete is applied as a radiation shield in radiotherapy centers, isotope and accelerator laboratories, and especially in nuclear facilities to keep the radiation exposure as low as possible according to the recommendation of international commission on radiological protection [3]. 
In a nuclear reactor, neutron particle is the most difficult to shield. Hydrogen is the most effective element in slowing down (thermalizing) neutrons over the entire energy spectrum. Fast neutrons are very penetrative, and not easy to attenuate. Neutron shielding requires slowing down energetic neutrons and absorbing slow ones with a shield material. Energetic neutrons are slowed down when they undergo scattering. Neutron scattering could be elastic or inelastic $[4,5]$. Different materials as hydrogen iron, graphite, water, polyethylene and concrete have suitable scattering cross - sections and hence can be used for moderating fast neutrons [6].

Neutron penetration in shielding is characterized by several parameters such as the macroscopic effective removal cross-sections for fast neutron $\Sigma_{R}$, the absorption macroscopic cross section of neutrons $\Sigma_{\mathrm{a}}$, scattering macroscopic cross section of thermal $\Sigma_{\mathrm{s}}$ thermal and epithermal $\Sigma_{\mathrm{s}}$ epithermal neutrons, relaxation length $\lambda\left(\mathrm{cm}^{-1}\right)$ and moderate ratio (MR). The mass attenuation coefficient $\left(\mu_{\mathrm{m}}\right)$ is the basic parameter which describes the interaction of gamma rays with shielding materials [7].

In this study, we have select boron carbide $\mathrm{B}_{4} \mathrm{C}$, Ilmenite $\mathrm{FeTiO}_{3}$, Ferro- boron $\mathrm{FeB}$, galena $\mathrm{PbS}$ and barite $\left(\mathrm{Baso}_{4}\right)$ to be studied as shielding for gamma and neutrons.

Boron carbide $\left(\mathrm{B}_{4} \mathrm{C}\right)$ is a ceramic material commonly used for neutron absorption in nuclear applications [8]. It has a high capture cross - section for thermal neutrons (3837 barns) making boron to be an attractive material for nuclear physics and technology. The use of boron carbide in the formulation of concretes is the advantages of neutron shielding for instruments and tools [9]. Ferro - boron $(\mathrm{Fe}-\mathrm{B})$ is a binary alloy of iron with boron content between $10 \%$ and $20 \%$ and is the lowest cost boron additive for steel and other ferrous metals. An alloy of iron is good for shielding of fast neutrons due to the high $\mathrm{Z}$ and low capture cross - section. Boron has large absorption cross section and ${ }^{10} \mathrm{~B}$ which $19.9 \%$ of nature boron has huge thermal neutron absorption cross-sections [6]. Galena $(\mathrm{PbS})$ mineral was used to produce of a high-density concrete. Galena $(\mathrm{PbS})$ is the main lead mineral. The molecular weight is $239.27 \mathrm{~g}$ and the ideal composition is $86.6 \%$ lead and $13.4 \%$ sulfur. It has low electrical conductivity, high coefficient of thermal expansion, high corrosion resistance and good lubricating property [10].

The heavy-weight materials such as Barite $\left(\mathrm{BaSO}_{4}\right)$ have been added into concrete as a good radiation shielding material and it is one of many construction product aggregates in heavy weight concrete. The higher the contents of Barite result in the higher attenuation coefficients [11]. Various products can be manufactured from this concrete on typical plants of concrete products and building nuclear power station landfills [12]. Ilmenite $\left(\mathrm{FeTiO}_{3}\right)$ concrete has a hardness of 5 to 6 . It is heavy weight high performance concrete, it has high strength and good radiation shielding against gamma rays. Such concretes have higher densities. The last studies showed that Ilmenite coarse aggregate gives better mechanical properties than the other aggregates [13].

The aim of the present work is a comparative study for radiation parameters of various concrete materials as a shield of gamma- rays and neutrons for nuclear facilities.

\section{2-Theoretical Background and Computational Work \\ 2.1 Gamma-Ray Interaction Parameter}

In the design of shielding materials, the linear attenuation coefficient $(\mu)$ which is defined as the probability of a radiation interacting with a material per unit path length, is important quantity. The mass attenuation coefficient $\mu_{\mathrm{m}}$ values for concretes are evaluated by the mixture rule,

$$
\mu_{m}=\Sigma_{i}^{n} w_{i}(\mu / \rho)_{i}
$$


Where $\rho$ is the density of the shielding materials, $w_{i}$ is the proportion by weight and $(\mu / \rho)_{i}$ is the mass attenuation coefficient of the $i_{\text {th }}$ element using WinXcom [14].

\subsection{Neutrons particle interaction parameters}

Neutrons are electrically neutral particles, during their passage through a material medium, they interact with the nuclei of atoms in two ways, either by diffusion or absorption. The interaction of neutrons with the atoms described by the total microscopic cross-section, expresses the probability that a neutron of a given energy interacts with the atoms of the traversed material and it is defined as the sum of the microscopic cross section scattering and the microscopic cross section absorption [15].

\section{a- The macroscopic effective removal cross sections of fast neutrons}

The effective removal cross-sections $\sum_{\mathrm{R}}$ for concrete can be calculated, with the Knowledge of the weight percentages $\mathrm{w}_{\mathrm{i}}$, and the values of $\left(\sum_{\mathrm{R}}\right)_{\mathrm{i}}$ for each of the consisting elements. This is achieved by following simple addition rules [16].$$
\sum_{\mathrm{R}}=\sum_{\mathrm{i}} \mathrm{W}_{\mathrm{i}}\left(\Sigma_{\mathrm{R}} / \rho\right)_{\mathrm{i}}
$$

Where $\mathrm{W}_{\mathrm{i}}, \rho$ and $\left(\Sigma_{\mathrm{R}} / \rho\right)_{\mathrm{i}}$ are respectively the partial density $\left(\mathrm{g} / \mathrm{cm}^{3}\right)$, density and mass removal cross section of the $i_{\text {th }}$ constituent. The values of $\left(\Sigma_{R} / \rho\right)_{i}\left(\mathrm{~cm}^{2} \mathrm{~g}^{-1}\right)$ of all the elements which constitute the shielding materials used in this study were taken from [16-20].

\section{b- The absorption and scattering (thermal and epithermal) macroscopic Cross section of \\ neutrons}

The macroscopic cross-section represents the effective target area of all of the nuclei contained in the

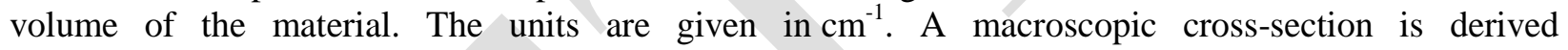
from microscopic cross-section and the atomic number density:

$$
\Sigma=\sigma . \mathrm{N}
$$

Here $\sigma$, which has units of $\mathrm{m}^{2}$, is the microscopic cross-section. Since the units of $\mathrm{N}$ (nuclei density) are nuclei $/ \mathrm{m}^{3}$. Most materials are composed of several chemical elements and compounds. For this reason most materials involve many cross-sections. The absorption and scattering (thermal and epithermal) macroscopic cross sections for neutrons are given by following equations:-

$$
\mathrm{N}_{\mathrm{i}}=\rho_{\mathrm{i}} \cdot \mathrm{N}_{0} / \mathrm{M}_{\mathrm{i}}
$$

Where $\mathrm{N}_{0}$ is the Avogadro's number $\left(\mathrm{N}_{0}=6.022 \times 10^{23}\right)$, is the number of particles (molecules, atoms) that is contained in the amount of substance given by one mole. Thus if $\mathrm{M}$ is the molecular weight, the ratio $\mathrm{N}_{0} / \mathrm{M}$ equals to the number of molecules in $1 \mathrm{~g}$ of the mixture. The number of molecules per $\mathrm{cm}^{3}$ in the material of density $\rho$ and the absorption macroscopic cross-section $\Sigma_{\mathrm{a}}$ of neutrons for mixtures are given by following equations:

$$
\sum_{a}=\sum_{i} \sigma_{a i} \cdot N_{i}
$$

Where $\sigma_{a i}$ is the absorption microscopic cross section of the $\mathrm{i}^{\text {th }}$ element.

The scattering (thermal and epithermal) macroscopic cross-section of neutrons $\Sigma_{\mathrm{s}}$ for mixtures are given by following equations:

$$
\sum_{s}=\sum_{i} \sigma_{s i} \cdot N_{i}
$$

Where $\sigma_{s i}$ is the scattering microscopic cross section of the $\mathrm{i}^{\text {th }}$ element for thermal or epithermal neutrons [21]. 


\section{c- Moderate Ratio}

The most complete measure of the effectiveness of a moderator is the moderating ratio. The moderating ratio is the ratio of the macroscopic slowing down power to the macroscopic cross section for absorption. The higher the moderating ratio, the more effectively the material performs as a moderator [21].

$$
\mathrm{MR}=\frac{\xi \Sigma_{s}}{\Sigma a}
$$

Where the logarithmic energy decrement $(\xi)$ is calculated by;

A: mass numbers.

$$
\xi=\frac{2}{A+\frac{2}{3}}
$$

\section{d- The Relaxation Length of absorption and scattering neutrons}

These quantities are usually designated by the symbol $\lambda_{\mathrm{a}}$ and $\lambda_{\mathrm{s}}$, where $\lambda_{\mathrm{a}}$ is equal to the average value of distance traveled by a neutron to interact by absorption in this mixtures, while $\lambda_{s}$ is equal to the average value of distance traveled by a neutron to interact by scattering [21].

$$
\lambda_{a}=\frac{1}{\sum_{a}}, \quad \lambda_{s}=\frac{1}{\sum_{s}}
$$

\section{3- Results and Discussions}

In the present work, the comparative study of gamma rays and neutrons shielding parameters for the standard concrete which is chosen as a primary shield and five materials (boron carbide $\left(\mathrm{B}_{4} \mathrm{C}\right)$, Ilmenite $\left(\mathrm{FeTiO}_{3}\right)$, Ferro-boron $(\mathrm{FeB})$, galena $(\mathrm{PbS})$ and barite $\left.\left(\mathrm{BaSo}_{4}\right)\right)$ which add separately to it with $20 \%$ in weight standard concrete material and some additive materials have been calculated using computational method. The Concrete containing different type of materials which used in our work have been chosen from several studies, which studied the mechanical and thermal properties of these materials. These studies have been shown that concrete containing different types of materials can be used as shields within reactors and nuclear facilities.

The elemental composition of standard concrete and standard concrete containing $20 \%$ of different materials are shown in table (1).

\subsection{The mass attenuation coefficient for gamma ray}

The mass attenuation coefficient for standard concrete and concrete containing different types of materials have been calculated at photon energy of $662 \mathrm{keV}$ by WinXcom program and shown in the Fig. (1).

From this Fig. we notice that the values of mass attenuation coefficient for all samples are in range from 0.0825 to $0.0891\left(\mathrm{~g} / \mathrm{cm}^{2}\right)$. The concrete containing galena $(\mathrm{PbS})$ material has highest value of mass attenuation coefficient due to its containing lead which has high atomic number, while concrete containing boron carbide $\left(\mathrm{B}_{4} \mathrm{C}\right)$ has lowest values. 
DOI : $\underline{\text { https://dx.doi.org/10.26808/rs.ed.i8v4.02 }}$

International Journal of Emerging Trends in Engineering and Development

Issue 8, Vol.3 (April- May 2018)

Available online on http://www.rspublication.com/ijeted/ijeted_index.htm

ISSN 2249-6149

Table 1 : The elemental composition and density of some concrete shielding materials

\begin{tabular}{|c|c|c|c|}
\hline Samples & Elements & Fraction \% & Density $\left(\mathrm{g} / \mathrm{cm}^{3}\right)$ \\
\hline \multirow[b]{3}{*}{ Standard concrete } & $\mathrm{H}$ & 0.10 & \multirow{6}{*}{2.34} \\
\hline & C & 0.23 & \\
\hline & $\mathrm{O}$ & 0.40 & \\
\hline \multirow{3}{*}{$\operatorname{Ref}[22]$} & $\mathrm{Mg}$ & 0.02 & \\
\hline & $\mathrm{Si}$ & 0.12 & \\
\hline & $\mathrm{Ca}$ & 0.12 & \\
\hline \multirow{7}{*}{$\begin{array}{l}\text { Concrete }+ \text { boron carbide } \\
\qquad \mathrm{B}_{4} \mathrm{C}\end{array}$} & $\mathrm{H}$ & 0.08 & \multirow{7}{*}{1.29} \\
\hline & B & 0.15 & \\
\hline & $\mathrm{C}$ & 0.23 & \\
\hline & $\mathrm{O}$ & 0.32 & \\
\hline & $\mathrm{Mg}$ & 0.02 & \\
\hline & $\mathrm{Si}$ & 0.10 & \\
\hline & $\mathrm{Ca}$ & 0.10 & \\
\hline \multirow{8}{*}{$\begin{array}{c}\text { Concrete + Ilmenite } \\
\mathrm{FeTiO}_{3}\end{array}$} & $\mathrm{H}$ & 0.08 & \multirow{8}{*}{2.25} \\
\hline & $\mathrm{C}$ & 0.18 & \\
\hline & $\mathrm{O}$ & 0.39 & \\
\hline & $\mathrm{Mg}$ & 0.02 & \\
\hline & $\mathrm{Si}$ & 0.10 & \\
\hline & $\mathrm{Ca}$ & 0.10 & \\
\hline & $\mathrm{Ti}$ & 0.06 & \\
\hline & $\mathrm{Fe}$ & 0.07 & \\
\hline \multirow{8}{*}{$\begin{array}{c}\text { Concrete }+ \text { ferro born } \\
\text { FeB }\end{array}$} & $\mathrm{H}$ & 0.08 & \multirow{8}{*}{2.33} \\
\hline & B & 0.03 & \\
\hline & $\mathrm{C}$ & 0.18 & \\
\hline & $\mathrm{O}$ & 0.32 & \\
\hline & $\mathrm{Mg}$ & 0.02 & \\
\hline & $\mathrm{Si}$ & 0.10 & \\
\hline & $\mathrm{Ca}$ & 0.10 & \\
\hline & $\mathrm{Fe}$ & 0.17 & \\
\hline \multirow{8}{*}{$\begin{array}{c}\text { Concrete + galena } \\
\text { PbS }\end{array}$} & $\mathrm{H}$ & 0.08 & \multirow{8}{*}{2.82} \\
\hline & S & 0.03 & \\
\hline & $\mathrm{C}$ & 0.18 & \\
\hline & $\mathrm{O}$ & 0.32 & \\
\hline & $\mathrm{Mg}$ & 0.02 & \\
\hline & $\mathrm{Si}$ & 0.10 & \\
\hline & $\mathrm{Ca}$ & 0.10 & \\
\hline & $\mathrm{Pb}$ & 0.17 & \\
\hline \multirow{8}{*}{$\begin{array}{l}\text { Concrete }+ \text { barite } \\
\text { BaSo4 }\end{array}$} & $\mathrm{H}$ & 0.08 & \multirow{8}{*}{1.21} \\
\hline & $\mathrm{C}$ & 0.18 & \\
\hline & $\mathrm{O}$ & 0.37 & \\
\hline & $\mathrm{Mg}$ & 0.02 & \\
\hline & $\mathrm{Si}$ & 0.10 & \\
\hline & S & 0.03 & \\
\hline & $\mathrm{Ca}$ & 0.10 & \\
\hline & $\mathrm{Ba}$ & 0.09 & \\
\hline
\end{tabular}




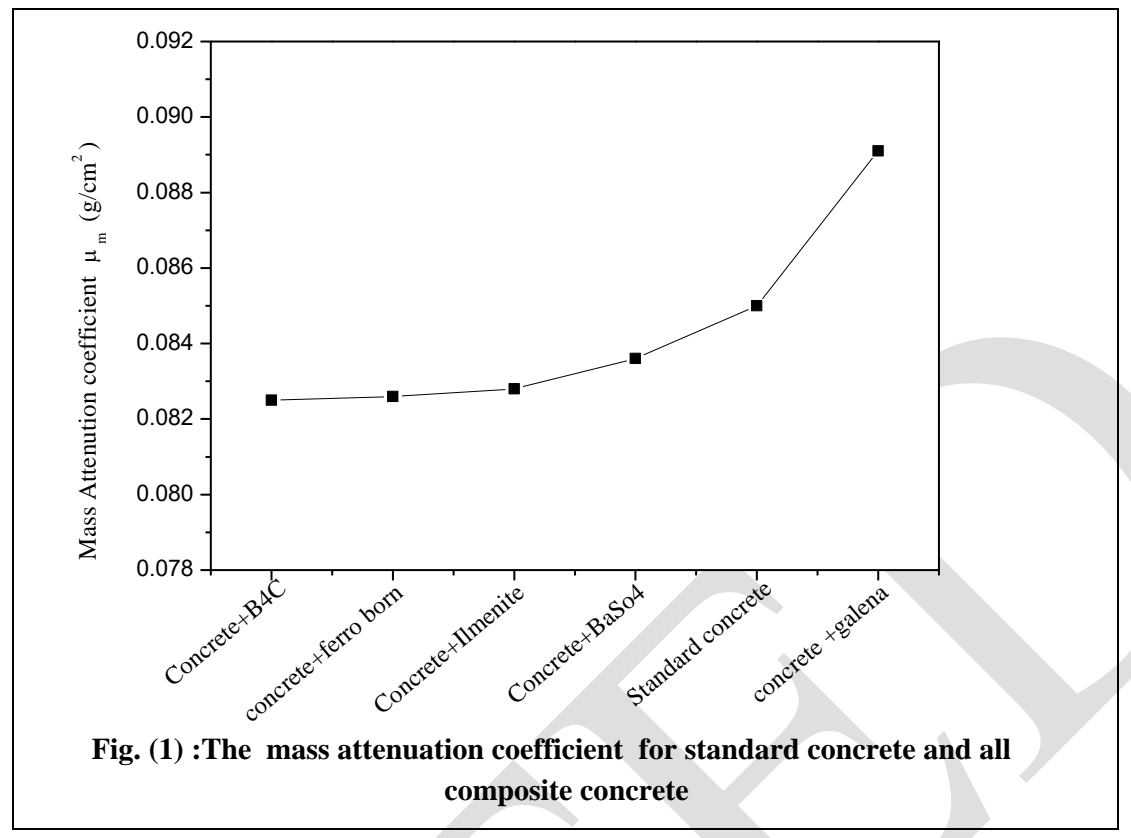

\subsection{Neutrons particle interaction parameters}

\section{a-The macroscopic effective removal cross sections of fast neutrons $\left(\Sigma_{R}\right)$}

The partial density $\left(\mathrm{g} / \mathrm{cm}^{3}\right)$ and the macroscopic effective removal cross-section $\Sigma_{\mathrm{R}}\left(\mathrm{cm}^{-1}\right)$ of fast neutrons for standard concrete and concrete containing different types of materials have been calculated and listed in Tables (2). From this table it can be notice that the macroscopic effective removal cross section depends on the elemental composition and partial density of materials.

It was observed that the $\Sigma_{R}$ was highest $(0.220)$ for concrete contains galena whereas all the remaining concrete samples range from 0.095 to 0.217 . The highest value of $\Sigma_{R}$ for concrete contains galena was observed due to contribution of $\mathrm{Pb}$ and $\mathrm{S}$ elements. Hydrogen in concrete content and sulfur in galena content have low mass numbers; they play an important role in the moderation of fast neutron and in the subsequent capture. When they combined with lead (heavy element), the more neutron attenuation properties can be obtained. It can be concluded that concrete containing galena sample is a superior neutron shielding material. The value of $\Sigma_{R}$ for concrete contains galena sample was found to be higher than standard concrete whereas other concrete samples were lower than it.

Concrete samples made of Galena showed a significantly better performance in radiation shielding against fast neutrons. 
Table (2): Calculations of the fast neutrons effective removal cross-sections for concrete samples

\begin{tabular}{|c|c|c|c|c|c|c|c|c|c|c|c|c|c|c|}
\hline \multirow[t]{2}{*}{ samples } & \multicolumn{13}{|c|}{ Partial density $\left(\mathrm{g} / \mathrm{cm}^{3}\right)$} & \multirow{2}{*}{$\begin{array}{c}\Sigma_{\mathrm{R}} \\
\left(\mathrm{cm}^{-1}\right)\end{array}$} \\
\hline & $\mathrm{H}$ & B & $\mathrm{C}$ & $\mathrm{O}$ & $\mathrm{Mg}$ & $\mathrm{Al}$ & $\mathrm{Si}$ & $S$ & $\mathrm{Ca}$ & $\mathrm{Ti}$ & $\mathrm{Fe}$ & $\mathrm{Pb}$ & $\mathrm{Ba}$ & \\
\hline standard & 0.23 & - & 0.53 & 0.93 & 0.04 & - & 0.28 & - & 0.28 & - & - & - & - & 0.217 \\
\hline $\begin{array}{c}\text { Concrete } \\
+\mathrm{B} 4 \mathrm{C}\end{array}$ & $\begin{array}{c}0.10 \\
4\end{array}$ & $\begin{array}{c}0.19 \\
9\end{array}$ & $\begin{array}{c}0.29 \\
8\end{array}$ & $\begin{array}{c}0.41 \\
4\end{array}$ & 0.02 & - & 0.12 & - & $\begin{array}{c}0.12 \\
4\end{array}$ & - & - & - & - & 0.111 \\
\hline $\begin{array}{l}\text { Concrete+ } \\
\text { Ilmenite }\end{array}$ & $\begin{array}{c}0.18 \\
0\end{array}$ & - & $\begin{array}{c}0.41 \\
4\end{array}$ & $\begin{array}{c}0.86 \\
9\end{array}$ & $\begin{array}{c}0.03 \\
6\end{array}$ & - & $\begin{array}{c}0.21 \\
6\end{array}$ & - & $\begin{array}{c}0.21 \\
6\end{array}$ & $\begin{array}{c}0.13 \\
7\end{array}$ & $\begin{array}{c}0.16 \\
2\end{array}$ & & - & 0.209 \\
\hline $\begin{array}{c}\text { Concrete } \\
+ \text { Ferro } \\
\text { born }\end{array}$ & $\begin{array}{c}0.18 \\
6\end{array}$ & $\begin{array}{c}0.07 \\
5\end{array}$ & $\begin{array}{c}0.42 \\
9\end{array}$ & $\begin{array}{c}0.74 \\
6\end{array}$ & $\begin{array}{c}0.03 \\
7\end{array}$ & & $\begin{array}{c}0.22 \\
4\end{array}$ & - & $\begin{array}{c}0.22 \\
4\end{array}$ & - & $\begin{array}{c}0.39 \\
1\end{array}$ & - & - & 0.185 \\
\hline $\begin{array}{c}\text { Concrete+ } \\
\text { galena }\end{array}$ & $\begin{array}{c}0.22 \\
6\end{array}$ & - & $\begin{array}{c}0.51 \\
9\end{array}$ & $\begin{array}{c}0.90 \\
2\end{array}$ & $\begin{array}{c}0.04 \\
5\end{array}$ & - & $\begin{array}{c}0.27 \\
1\end{array}$ & $\begin{array}{c}0.07 \\
6\end{array}$ & $\begin{array}{c}0.27 \\
1\end{array}$ & - & - & 0.488 & - & 0.220 \\
\hline $\begin{array}{c}\text { Concrete+ } \\
\text { barite }\end{array}$ & $\begin{array}{c}0.09 \\
7\end{array}$ & & $\begin{array}{c}0.23 \\
3\end{array}$ & $\begin{array}{c}0.45 \\
0\end{array}$ & $\begin{array}{c}0.01 \\
9\end{array}$ & - & $\begin{array}{c}0.12 \\
1\end{array}$ & $\begin{array}{c}0.03 \\
2\end{array}$ & $\begin{array}{c}0.12 \\
1\end{array}$ & - & - & - & 0.109 & 0.095 \\
\hline
\end{tabular}

b-The absorption $\Sigma_{a}$ and scattering (thermal $\Sigma_{s}$ thermal and epithermal $\Sigma_{s}$ epithermal) macroscopic cross section of neutron.

The calculated values for absorption and scattering (thermal and epithermal) macroscopic cross section of neutrons for all concrete materials are shown in fig.(2). Where the values of $\Sigma_{\text {a }}$ ranges from 0.00233 to $15.9\left(\mathrm{~cm}^{-1}\right)$, the values of $\Sigma_{\mathrm{s}}$ thermal ranges from 0.147 to 2.04 and the values of $\quad \Sigma_{\text {s epithermal }}$ ranges from 0.146 to 0.264 .

From this figure, it's observed that the value of absorption macroscopic cross section $\Sigma_{\mathrm{a}}$ is high for concrete containing boron carbide $\left(\mathrm{B}_{4} \mathrm{C}\right)$, then the value decreases rapidly for concrete containing Ferro- boron, then the lower values are in the other materials. Boron is commonly used as a neutron absorber due to the high neutron cross-section. While the values of scattering thermal and epithermal macroscopic cross section are approximately constant for all materials except the concrete containing barite $\left(\mathrm{BaSO}_{4}\right)$ material, this is due to hydrogen in concrete content, sulfur and oxygen in barite martial. In barite concrete slowing down of neutrons is done by hydrogen, sulfur and oxygen which have low mass number elements as a result of scattering reaction. So, the effect of the combination of light elements can reduce neutron energy. 




\section{c- Moderate Ratio}

The calculated moderating ratio for all concrete materials are shown in fig. (3). The moderating ratio values ranged from 0.00263 to 43 . The highest value of moderating ratio is 43 for concrete containing barite materials, so it is more effectively performs as a moderator. Barite materials have low mass number elements play an important role in the moderation of neutron and in the subsequent capture.

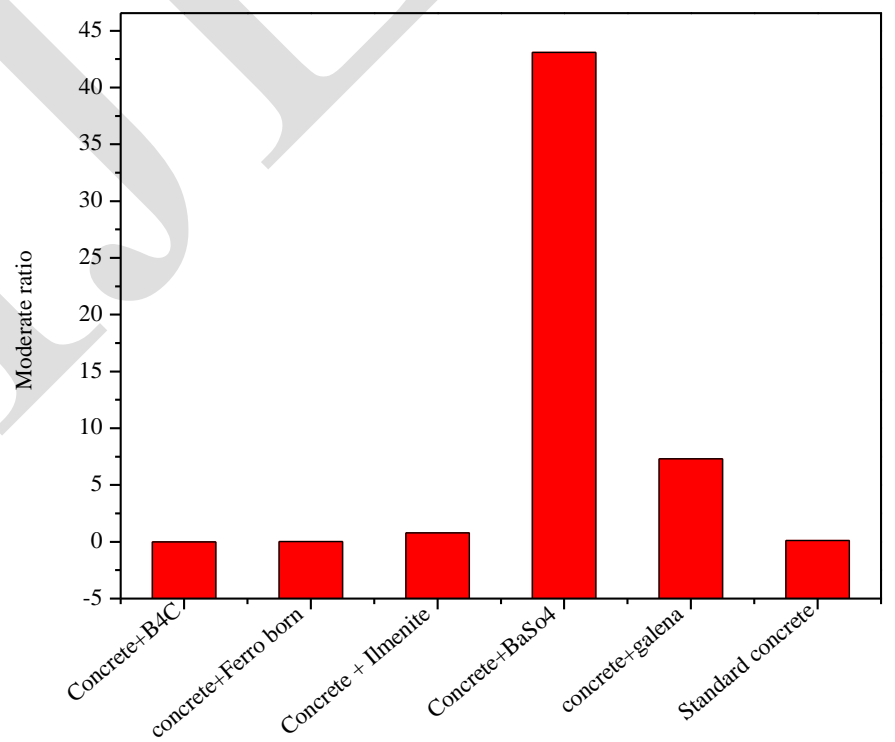

Fig. (3):- The moderate ratio for concrete samples 


\section{d- Relaxation Length}

The calculated relaxation Length for absorption $\lambda_{\mathrm{a}}$ and scattering $\lambda_{\mathrm{s}}$ are shown in Fig. (4). The values of $\lambda_{\mathrm{a}}$ ranges from 0.0628 to 429 , while $\lambda_{\mathrm{s}}$ ranges from 0.489 to 6.8 .

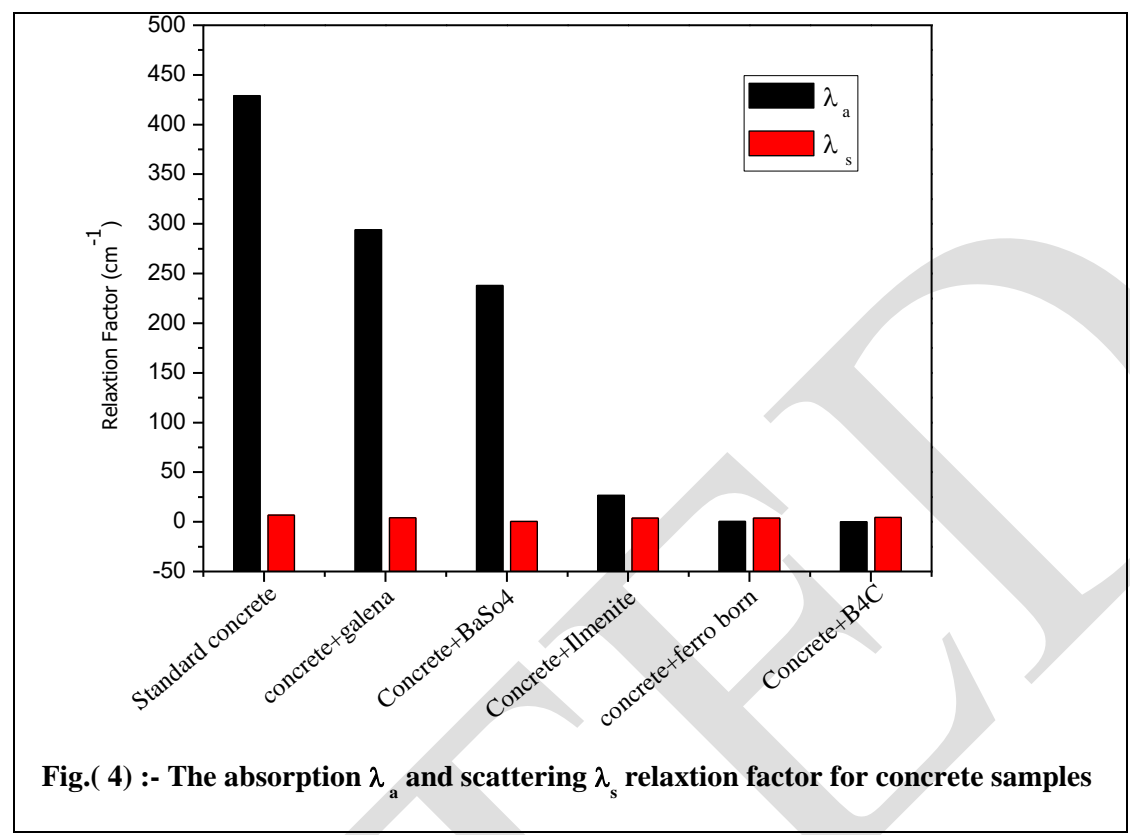

That means the neutron must travel an average of $0.0628 \mathrm{~cm}$ in concrete contain $\mathrm{B}_{4} \mathrm{C}$ to interact by absorption, but it must travel an average of $0.489 \mathrm{~cm}$ in concrete contain $\mathrm{BaSo}_{4}$ to interact by scattering.

\section{3 -Conclusion:}

Based on the results obtained, it can be concluded that, the selection of a shielding material for fast neutrons requires the knowledge of the macroscopic effective removal cross-section. The total cross section of atom is dependent on the neutron energy so often an element will be a good thermal neutron absorber, however will not be able to absorb fast neutrons. In some nuclear facilities, the neutron shield system is consists of three parts. It must be consists of a material layer to slow down neutrons, layer to absorb them and layer to stop any residual radiation produced in this process. The best materials for shielding neutrons and gamma rays must be:

Slow down:- First point can be satisfied only by material containing light atoms. Concrete containing barite material is the best one for moderate neutron without total absorbed.

Absorb this slow neutron. Thermal neutrons can be easily absorbed by capture in materials with high neutron capture cross sections. Concrete containing boron carbide is the best one for absorption of neutrons. The absorption of neutrons is accompanied by strong emission of gamma rays. Therefore additional shield is necessary to attenuate the gamma rays. This phenomenon is less important for boron as a neutron absorption material. For this reason, materials containing boron are very effective neutron shield.

Gamma ray. Galena concrete had showed good shielding for gamma ray and fast neutrons in comparison with all other samples. Galena concrete is the best non-radioactive shield for applications such as shielding megavoltage radiotherapy rooms as well as nuclear reactors. 
According to the theoretical results, it is clear that concrete by adding different proportions of these materials can significantly enhance the radiation shielding properties of concrete. The results of this study will provide some useful information for shielding applications against gamma rays and neutrons.

\section{References}

I. Muhammad Syahir Sarkawi, Muhammad Rawi Mohamed Zain, Mohamad Hairie Rabir, Faridah Mohamad Idris , Jasman Zainal, "Radiation Shielding Properties of Ferro-boron Concrete", IOP Conf. Series: Materials Science and Engineering 298, (2018).

II. Özavcı, S. and B. Çetin, "Radiation Shielding Properties of Concretes Including quiclime $(\mathrm{CaO}) "$. AIP Conference Proceedings, 1815 (1): p. 130009, (2017).

III. Murray, R.L. and K.E. Holbert, Chapter 11 - Radiation Protection in Nuclear Energy (Seventh Edition), Butterworth-Heinemann: Boston. pp. 153-176, (2015).

IV. D. Sariyer, R. Küçer , N. Küçer, "Neutron Shielding Properties of Concretes Containing Boron Carbide and Ferro - Boron", Procedia-Social and Behavioral Sciences 195, 1752 1756, (2015).

V. Nyarku, M., Keshavamurthy, R. S., Subramanian, V. D., Haridas, A., \& Glover, E. T. "Experimental Neutron Attenuation Measurements in Possible Fast Reactor Shield Materials". Annals of Nuclear Energy, 53, 135-139, (2013).

VI. Abdullah, Y., Yusof, M. R., Mustaffa, R., Mohamed, A. A., Ariffin, F. N. T., \& Abdullah, N. E. "Properties of Concrete / Boron Carbide As Neutron Shielding Materials", Journal of Nuclear and Related Technologies, 8 (2), (2011).

VII. Y. Elmahroug1, B. Tellili2 \& C. Souga3, "Calculation of Gamma and Neutron Shielding Parameters for Some Materials Polyethylene-Based", International Journal of Physics and Research (ijpr), ISSN 2250-0030, vol.3, Issue 1, 33-40, (2013).

VIII. Kharita, M. H., Yousef, S., \& AlNassar, M.," Review on the Addition of Boron Compounds to Radiation Shielding Concrete", Progress in Nuclear Energy, 53, 207-211, (2011).

IX. Martin, J. E., "Physics for Radiation Protection a Handbook" Second Edition, Wiley VCH Verlag GmbH \& Co. KGaA, Weinheim, (2006).

X. S.M.J. Mortazavi, M.A. Mosleh-Shirazi, M.R. Maheri, H.Yousefnia, S. Zolghadri, A. Haji-pour., "Production of An Economic High-Density Concrete For Shielding Megavoltage Radiotherapy Rooms and Nuclear Reactors", Iran. J. Radiat. Res.; 5 (3): 143-146, (2007).

XI. Akkurt, C. Basyigit, S. Kilincarslan and B. Mavi, "The Shielding of Gamma-Rays by Concretes Produced with Barite". Progress in Nuclear Energy, 46, 1-11, (2010). 
XII. Andrei Smolikov, Viacheslav Pavlenko, Nicolai Shapovalov, Olga Kuprieva, Alexander Solokha., "Super Heavy Nano-Reinforcing Concrete for Quick Neutron Reactors', International Journal of Research in Mechanical Engineering \& Technology ,IJRMET Vol. 3, Issue 2, ISSN : 2249-5762 (Online) | ISSN : 2249-5770, May - Oct (2013).

XIII. M.A. El-Sarraf, A. El-Sayed Abdo, M.A. Abdul-Wahab, "Usability of Epoxy/Ilmenite Composite Material As an Attenuator For Radiation and a Restoration Mortar For Cracks", Annals of Nuclear Energy 60, 362-367, (2013).

XIV. Gelward L, Guilbert N, Jensen KB, Levring H. "WinXcom-a Program for Calculating X-Ray Attenuation Coefficients", J. Radi. Phys. And Chem., 71, pp. 653-654, (2004).

XV. J.K. Shultis and R.E. Faw, "Fundamentals of Nuclear Science and Engineering" 2nd.ed. CRC Press, (2008).

XVI. Kaplan, M.F., "Concrete Radiation Shielding", John and Wiley, New York, USA (1989).

XVII. A.B. Chilton, J.K. Shultis and R.E. Faw., "Principles of Radiation Shielding", Prentice- Hall, New York. (1984).

XVIII. A.E. Profio, "Radiation Shielding and Dosimetry”. Wiley, New York (1979).

XIX. El-Khayatt, A. M and El-Sayed Abdo, "A. MERCSFN: A program For the Calculation of Fast Neutron Removal Cross Section in Composite Shields", Ann. Nucl. Energy Vol. 36, Page 832-836, (2009).

XX. A.M. El-Khayatt., "Calculation of Fast Neutron Removal Cross-Sections for Some Compounds and Materials", Ann. Nucl. Energy. 37: 218-222, (2010).

XXI. Doe fundamentals handbook nuclear physics and reactor theory volume 1 of 2 , U.S. Department of energy FSC-6910Washington, D.C. 20585, January, (1993).

XXII. Muhammad Syahir Sarkawi, Muhammad Rawi Mohamed Zain, Mohamad Hairie Rabir, Faridah Mohamad Idris, Jasman Zainal, "Radiation Shielding Properties of Ferroboron Concrete", IOP Conf. Series: Materials Science and Engineering 298 (2018). 